\title{
CONTRIBUIÇÕES DA SOCIOLOGIA DAS PROFISSÕES PARA A ANÁLISE DAS PROFISSÕES DE ARQUIVISTA E MUSEÓLOGO NO BRASIL
}

\author{
CONTRIBUTIONS OF SOCIOLOGY OF THE PROFESSIONS FOR THE ANALYSIS \\ OF ARCHIVIST AND MUSEOLOGIST PROFESSIONS IN BRAZIL
}

\begin{abstract}
Thiara dos Santos Alves ${ }^{1}$
1 Arquivista do Centro Federal Tecnológico Celso Suckow da Fonseca (CEFET/RJ), Doutoranda no Programa de Pós-Graduação em Ciência da Informação do Instituto Brasileiro de Informação em Ciência e Tecnologia/Universidade Federal do Rio de Janeiro (IBICT/UFRJ), Brasil, e-mail: thialves@yahoo.com.br
\end{abstract}

\author{
ART ICLE INFO \\ Article history: \\ Received 2019-02-26 \\ Accepted 2019-06-17 \\ Available online 2019-06-17
}

Palavras-chave: Sociologia das Profissões. Arquivista. Museólogo.

Keywords: Sociology of Professions. Archivist. Museologist.

RESUMO. Este artigo consiste em uma reflexão teórica, realizada a partir de levantamento bibliográfico, sobre a contribuição da Sociologia das Profissões para a análise das profissões de Arquivista e Museólogo no Brasil. Buscou-se desenvolver, sempre que possível convergindo para a realidade dos Arquivistas e dos Museólogos, os conteúdos da Sociologia das Profissões sobre a centralidade do conhecimento científico e o papel do Estado nas determinações profissionais e também sobre as profissões na sociedade democrática e a organização profissional. Este trabalho demonstrou que 0 diploma de nível superior é um critério determinante para distinguir os conceitos de profissão e ocupação e que o Estado exerce um papel relevante nas determinações profissionais. Destacou-se que cada grupo profissional possui um campo de atividade exclusivo e um campo residual de atuação profissional, no qual as profissões concorrem pelo mercado de trabalho. O controle legal sobre as profissões de Arquivistas e Museólogos, por meio da formação universitária e da regulamentação profissional, garante-Ihes o exercício jurisdicional sobre certas atividades exclusivas; no entanto, não os exime da investida de alguns grupos, como dos Historiadores, pois a disputa é inerente ao campo das profissões. Na reflexão teórica aqui apresentada, evidenciou-se que as organizações profissionais são as responsáveis pela definição de laços de confiança púbica nas profissões e entre os profissionais. O campo museológico está melhor representado pelo Conselho Federal de Museologia e pelos Conselhos Regionais de Museologia. Ao passo que as associações estaduais é o tipo de organização profissional que se sobressai no campo arquivístico.

ABSTRACT. This article consists of a theoretical reflection, made from a bibliographic research, on the contribution of the Sociology of Professions to the analysis of the professions of Archivist and Museologist in Brazil. Sought to developed, whenever possible converging to the reality of Archivists and Museologists, the contents of the Sociology of Professions on the centrality of scientific knowledge and the role of the State in professional determinations, as well as on the professions in democratic society and professional organization. This work demonstrated that the higher-level diploma is a determining criterion to distinguish the concepts of profession and occupation and that the State plays a relevant role in professional determinations. It was pointed out that each professional group has an exclusive field of activity and a residual field of professional activity, in which professions compete for the labor market. Legal control over the professions of Archivists and Museologists, through university education and professional regulation, guarantees them the jurisdictional exercise of certain exclusive 
activities; however, does not exempt them from the onslaught of some groups, such as Historians, because the dispute is inherent in the field of professions. In the theoretical reflection presented here, it was evidenced that the professional organizations are responsible for the definition of bonds of public trust in the professions and among professionals. The museological field is better represented by the Federal Council of Museology and by the Regional Councils of Museology. While the state associations is the type of professional organization that stands out in the archival field.

\section{Introdução}

Este trabalho é parte do referencial teórico da dissertação de mestrado $A$ família ocupacional "Arquivistas e Museólogos": posicionamento na Classificação Brasileira de Ocupações e perfil de emprego (ALVES, 2016), defendida no Programa de Pós-Graduação em Ciência da Informação da Universidade Federal de Minas Gerais. Tal dissertação apresentou o posicionamento dos Arquivistas e dos Museólogos na Classificação Brasileira de Ocupações; explicou o motivo pelo qual estes profissionais formam uma única Família ocupacional; e caracterizou o perfil de emprego formal dos "Arquivistas e Museólogos", a partir dos dados estatísticos da Relação Anual de Informações Sociais.

O artigo aqui apresentado consiste em uma reflexão teórica, realizada a partir de levantamento bibliográfico, sobre a contribuição da Sociologia das Profissões para a análise das profissões de Arquivista e Museólogo no Brasil. Os subsídios das Ciências Humanas e Sociais são importantes para a área da informação e do trabalho e neste artigo buscou-se desenvolver, sempre que possível convergindo para a realidade dos Arquivistas e dos Museólogos, os conteúdos da Sociologia das profissões sobre a centralidade do conhecimento científico e o papel do Estado nas determinações profissionais e também sobre as profissões na sociedade democrática e a organização profissional.

Cabe destacar que a contribuição da Sociologia das Profissões, da Sociologia do Trabalho e áreas afins para os campos de estudo sobre informação, educação e trabalho aumentou nos últimos anos. Tal situação pode ser verificada na análise de Crivellari e Cunha (2009), a partir dos anais do Encontro Nacional de Pesquisa em Ciência da Informação (ENANCIB), no período de 2003 a 2008.

\section{A centralidade do conhecimento científico e o papel do estado nas determinações profissionais}

$\mathrm{Na}$ Sociologia das Profissões, as diversas abordagens teórico-metodológicas, tanto as funcionalistas quanto as fenomenológicas ou marxistas, consideram que o conhecimento formal, abstrato de nível superior, é pré-requisito para classificar o que é uma profissão. Crivellari e Cunha (2004) usam este mesmo critério para distinguir os conceitos de profissão e ocupação, destacando que a profissão é formada por um corpo de saberes científicos, que 
o diploma é o principal fundamento do direito à autoridade e que as organizações profissionais e o Estado desempenham um importante papel normalizador das profissões.

A abordagem sistêmica da Sociologia das Profissões tem como marco os estudos de Abbott (1988), o qual define profissões como "grupos ocupacionais exclusivos que aplicam conhecimentos mais ou menos abstratos a casos particulares, com o objetivo de resolver problemas para uma clientela" (ABBOTT, 1988, p. 8). Rodrigues (2002) apresenta os pressupostos da formulação de Abbott, resultantes de estudo crítico sobre os conceitos da tradição disciplinar da Sociologia das Profissões:

1) O estudo das profissões deve centrar-se nas áreas de actividade sobre as quais detêm o direito de controlar a prestação de serviços - jurisdições -, isto é, no tipo de trabalho que desenvolvem e nas condições de exercício da actividade, e não apenas nas suas características culturais e organizativas;

2) as disputas, os conflitos e a competição em áreas jurisdicionais constituem a dinâmica de desenvolvimento profissional, pelo que a história das profissões é a história das condições e consequências da apresentação de reclamação de jurisdição, por parte dos grupos ocupacionais, sobre áreas de actividade que já existem, são criadas ou estão sob o domínio de qualquer grupo;

3) as profissões existem no conjunto do sistema ocupacional e não como entidades isoladas, pelo que sua abordagem deve considerar o sistema de interdependência que caracteriza as relações entre os grupos profissionais;

4) o principal recurso na disputa jurisdicional, e a característica que meIhor define profissão, é o conhecimento abstracto controlado pelos grupos ocupacionais: a abstração confere capacidade de sobrevivência no competitivo sistema de profissões, defendendo de intrusos, uma vez que só um sistema de conhecimento governado por abstracção permite redefinir e dimensionar novos problemas e tarefas;

5) os processos de desenvolvimento profissional são multidireccionais, não se podem sustentar as teses de tendência (profissionalização ou desprofissionalização) (RODRIGUES, 2002, p. 94-95).

Diante das competições entre grupos profissionais, Abbott (1988) aponta que a vulnerabilidade das jurisdições das tarefas profissionais é determinada pela própria natureza do trabalho profissional. Este trabalho incide sobre problemas humanos que serão resolvidos pelos peritos/experts. A diversidade dos problemas a serem solucionados pode ser vista em extremos variados, entre os quais se destaca o contraponto dos problemas objetivos (propostos por imperativos tecnológicos ou naturais) e dos subjetivos (dados culturalmente), que se distinguem pela possibilidade da resolução ocorrer por meio do trabalho cultural (RODRIGUES, 2002). A manutenção da jurisdição profissional depende da importância de seu sistema de conhecimento, assim "quanto maior o poder de abstração teórica de uma profissão, mais sólida ela será no espaço social e no sistema profissional" (CRIVELLARI; CUNHA, 2009, p. 140). Esta solidez revela-se na garantia de monopólio do espaço profissional, pois a sistematização do conhecimento permite a oferta de serviços com maior segurança, qualidade e eficácia.

"O fenômeno central da vida profissional é a ligação entre a profissão e o trabalho - 0 que Abbott denomina de jurisdição" (CUNHA; CRIVELLARI, 2004, p. 42). Dentro desta lógica, 
o conhecimento acadêmico é o diferencial que formaliza o saber-fazer da profissão, a partir do critério da lógica e da racionalidade em detrimento da prática e da eficácia. "Jurisdição seria o laço que se estabelece entre o grupo profissional e a área de conhecimento sob seu controle" (BARBOSA, 1993, p. 7); portanto, é preciso também "reconhecimento social da estrutura cognitiva, através de direitos exclusivos, os quais podem incluir o monopólio da prática profissional, o pagamento público dos serviços, o direito de autodisciplina, o controlo da formação, do recrutamento e das licenças" (RODRIGUES, 2002, p. 97).

Outro fator importante na definição da jurisdição profissional é a ação dos diferentes tipos de organização social das profissões (associações, sindicatos, conselhos profissionais, etc), pois eles influenciam na escolha das reclamações jurisdicionais e no êxito de se efetivarem estas pretensões (RODRIGUES, 2002). Os diferentes saberes produzidos resultam nas diferentes profissões e o Estado elimina os concorrentes através de mecanismos legais, como, por exemplo, através da regulamentação das profissões e da delegação de autoridade aos conselhos de classe profissional para autorizar e fiscalizar o exercício profissional. Além disso, o Estado também pode incentivar o crescimento de um grupo profissional através de estímulos para a criação de cursos em instituições públicas.

No Brasil, as profissões de Arquivista e Museólogo são regulamentadas, respectivamente, pela Lei ํo. 6.546/78 e pela Lei №. 7.287/84. De acordo com a legislação, Arquivista atualmente é o diplomado em curso superior de Arquivologia, já o título de Museólogo é atribuído atualmente tanto ao graduado em curso superior de Museologia quanto ao pós-graduado, em nível de Mestrado e Doutorado, em Museologia. Os cursos mais recentes de Arquivologia e Museologia, por exemplo, foram impulsionados, a partir de 2007, pelo Programa de Apoio a Planos de Reestruturação e Expansão das Universidades Federais (REUNI), regulado pelo Decreto $n^{\circ}$. 6.096/2007. O REUNI, como parte do Plano Nacional de Educação do Ministério da Educação, foi responsável pela criação de seis cursos de Arquivologia e nove de Museologia (TANUS, 2013).

Rodrigues (2002) aponta que a origem do poder profissional, de acordo com as ideias de Abbott (1988), é diversa e indica algumas fontes deste poder: a jurisdição subjetiva (imposta culturalmente); a proteção do Estado, "muitas vezes requerida sob a retórica do afastamento de perigos e da criação de disciplina profissional" (RODRIGUES, 2002, p. 102); a aliança com classes sociais. O poder profissional, segundo Abbott (1988), pode ser exercido nos campos de jurisdição legal (o Estado estabelecendo monopólios de prestação de serviços e designando entidades licenciadoras das profissões e de controle legal dos profissionais), do público (estratégias de comunicação social) e de situação de trabalho (mecanismos de reforço da jurisdição legal, controle da linguagem profissional e da subordinação direta e simbólica).

No âmbito da situação de trabalho, o êxito da jurisdição está relacionado à evidenciação da competência do grupo profissional; no âmbito legislativo, está relacionado ao envolvimento político. Assim, no estudo de nível público e legal da fixação de jurisdição 
profissional, "os atributos possuídos pelas profissões [...] podem ou não ser um facto; o que é importante é que a elite social, bem como os legisladores, esteja convencida da realidade de tais atributos" (RODRIGUES, 2002, p. 105).

Embora sejam múltiplas as origens do poder profissional, "o saber, os saberes, as competências e o conhecimento científico são um elemento essencial em qualquer das abordagens das profissões" (RODRIGUES, 2002, p. 111). O conhecimento é fundamental para a construção do poder profissional e para manter e ampliar este poder é essencial a articulação com projetos políticos (RODRIGUES, 2002). Vale ressaltar que o conhecimento científico não é condição suficiente para os processos de profissionalização, mas é condição necessária e indispensável.

O Estado tem um papel ativo nas práticas profissionais que pode se dar, por exemplo, pelo emprego de profissionais, pela sua formação, pela regulamentação de profissões, ou pelas políticas públicas com consequências para estas. A regulamentação profissional é uma importante ação estatal, pois "as profissões regulamentadas há mais tempo têm uma condição mais favorável à prevenção do desemprego estrutural, à manutenção da mão de obra qualificada, à possibilidade de mobilidade ascendente e à estabilidade" (OLIVEIRA; CRIVELLARI, 2013).

A Constituição da República Federativa do Brasil, de 1988, institui, entre os direitos e garantias fundamentais, o livre o exercício de qualquer trabalho, ofício ou profissão, sendo necessário atender as qualificações profissionais que a lei estabelecer. Assim, é lícito exercer qualquer tipo de trabalho, ofício ou profissão, exceto em casos especiais, quando o interesse público prevalecer sobre os direitos individuais, devido aos riscos inerentes à execução da atividade e para proteger a coletividade (COSTA; VALENTE, 2008). Nestas situações, as profissões, com conhecimentos técnicos e científicos desenvolvidos, passam a ser regulamentadas através de lei que limita o livre exercício da atividade profissional ao fixar as competências profissionais e os requisitos de qualificação para exercê-la.

Todas as profissões relacionam-se com o Estado em alguma medida, mas esta relação é bem evidente no caso das profissões burocráticas. Os objetivos, os valores basilares e os ideais das profissões burocráticas estão de acordo com os interesses ideológicos do Estado. O Estado assegura à estes tipos de profissões as licenças, a clientela pública e o seu pagamento. As profissões burocráticas, por sua vez, retribuem o Estado por meio de serviços eficientes e aceitando limites à sua autonomia profissional, principalmente limitações sobre a definição e escolha dos clientes e sobre a possibilidade de ter clientes privados (RODRIGUES, 2002).

$\mathrm{Na}$ origem da Arquivologia, observam-se os "aspectos pragmáticos vinculados às práticas burocráticas visando [sic] eficácia e eficiência na guarda e preservação de arquivos, notadamente os públicos" (FONSECA, 2005, p. 55). Na gestão racional do Estado burocrático, 
"os documentos e os arquivos são, [...], a expressão material mais clara e o mais firme sustentáculo da natureza institucional da administração pública" (AMPUDIA MELO, 1998, p.38 apud FONSECA, 2005, p. 38).

O sucesso e a força profissional têm estrita relação com as alianças políticas, que podem ser construídas pelas associações, sindicatos e conselhos profissionais. O espaço ocupado por uma profissão e os espaços do campo jurisdicional podem ser divididos em heartland - que é o núcleo central de uma profissão, com seu controle completo e legal hinterland - periferia do heartland, onde surgem os novos espaços profissionais, por ser nesta periferia onde reside as confluências entre profissões próximas e onde os profissionais são mais valorizados por sua expertise do que por seu diploma, originando as lutas de poder pelas jurisdições - e horizon - margens do hinterland (CRONIN; STIFFLER; DAY, 1983 apud CUNHA; CRIVELLARI, 2004).

No Brasil, entre as profissões de nível Superior, apenas Direito e Medicina são profissões fortes, com instrumentos de controle de mercado; nem mesmo as Engenharias, que são profissões tradicionais, são tão fortes quanto as outras duas anteriormente citadas (BONELLI, 1993). Portanto, a Arquivologia e a Museologia são fracas profissionalmente, mas isto não é uma característica intrínseca apenas a elas. "O fato de a força ser uma característica de pouquíssimas profissões significa que há, para as demais, oportunidades de interagir no sistema profissional, conquistando e perdendo espaços nas competições que o movimentam" (BONELLI, 1993, p. 53). Outro fator que interfere no baixo poder da organização social interna da profissão de Arquivista é o local de trabalho, uma vez que esta profissão está vinculada, geralmente, a instituições detentoras de arquivos, desempenhando uma atividademeio nestes espaços.

Há locais que tendem a beneficiar certas profissões com domínio exclusivo. Hospitais, por exemplo, oferecem aos médicos o controle das decisões sobre o todo o trabalho que é realizado nas suas dependências, por eles próprios e pelas demais profissões e ocupações envolvidas no trabalho hospitalar. [...]. Em outros casos, o local de trabalho tem papel diferente. É o caso de profissões que nasceram ligadas a certas instituições e têm sido fortemente influenciadas por esse fato, como a biblioteconomia e o magistério de escola básica. Nessas, os objetivos do trabalho são em geral ditados por outros grupos, que detém [sic] controle sobre a instituição, e não a profissão que nela trabalha. São, de certa forma, profissões às quais faltam certos aspectos do poder (MUELLER, 2004, p. 40).

Abbott (1988) estuda as profissões "como sistema de inter-relações ou uma ecologia: cada uma delas influencia e é influenciada pelas outras" (CRIVELLARI; CUNHA, 2009, p. 140). Se os limites de uma profissão não estão bem definidos, pode ocorrer uma disputa por espaço com profissionais de outras áreas que "invadem" o campo (CUNHA; CRIVELLARI, 2004). No âmbito desta competição interprofissional, por exemplo, os Museólogos e os Arquivistas disputam com os Historiadores o desempenho das atividades especializadas da área da cultura. A Arquivologia e a Museologia surgiram e, inicialmente, se desenvolveram a 
partir de aproximações científicas e positivistas com a História, "adquirindo, de início, a condição subsidiária de 'ciências auxiliares' que, mais tarde, foi posta em causa e substituída por uma infrene (e, em nossa opinião, indefensável) estratégia autonomista” (SILVA, 2002, p. 576).

No século $X X$, a distinção entre os documentos de guarda permanente e os documentos de guarda corrente e intermediária criaram condições para um lento, mas progressivo, afastamento entre Historiadores e Arquivistas (MIRANDA, 2011). Inclusive, a importância dos arquivos correntes nas instituições promoveu uma aliança entre a Arquivologia e a Biblioteconomia/Documentação (MARQUES, 2011). Os bacharéis e docentes de Biblioteconomia e de História contribuíram destacadamente para a formulação dos cursos de Arquivologia no Brasil (DUARTE, 2006-2007).

O movimento para a regulamentação das profissões de Arquivista e de Técnico de Arquivo foi conduzido pela Associação dos Arquivistas Brasileiros (SANTOS, 2008). No Brasil, é por meio da regulamentação profissional que o Estado define e circunscreve a jurisdição de uma profissão que, geralmente, está atrelada aos diplomas de graduação (MARQUES, 2011). Em 28 de março de 1978, foi publicado, no Diário do Congresso Nacional, o Projeto de Lei 4.767/78, que foi transformado na Lei Ordinária no 6.546/78, que dispõe sobre a regulamentação da profissão de Arquivista e de Técnico em Arquivo. Vale destacar que esta lei vigora há mais de 40 anos e nunca passou por alterações. Isto faz com que haja uma evidente defasagem nas atribuições dos Arquivistas, necessitando, portanto, de revisão (SOUZA, 2011).

A competição interprofissional entre Arquivistas e Historiadores pode ser observada nas investidas dos Historiadores de terem sua profissão regulamentada. "Richardson (1987) [...] enfatiza que a competição interprofissional consiste em importante fator no processo de profissionalização, por meio da definição dos padrões de formação, da apropriação dos atributos simbólicos do profissionalismo e do licenciamento das atividades (CRIVELLARI; CUNHA, 2009, p. 141).

Em 2014, a Comissão de Constituição e Justiça e de Cidadania, da Câmara dos Deputados, aprovou o Projeto de Lei no 4.699/12, que regulamenta a profissão do Historiador. Entre as atribuições do Historiador, esta proposta prevê: "assessoramento, organização, implantação e direção de serviços de documentação e informação histórica" (BRASIL, 2012) e "assessoramento voltado à avaliação e seleção de documentos, para fins de preservação" (BRASIL, 2012). Estas duas atribuições que seriam competências exclusivas do Historiador conflitam com as seguintes atribuições do Arquivista estabelecidas por lei: "planejamento, orientação e acompanhamento do processo documental e informativo" (BRASIL, 1978) e “orientação da avaliação e seleção de documentos, para fins de preservação" (BRASIL, 1978). 
Para ratificar a importância dos Historiadores nos arquivos, a Associação Nacional de História (ANPUH) organizou, em 2012, o evento O perfil profissional dos Historiadores atuantes em arquivos. A plenária final deste acontecimento resultou em um documento que levou o mesmo título do evento. Foram cinco grupos de trabalho - "Formação do historiador para atuar em arquivos"; "Os historiadores e a difusão cultural em arquivos"; "Os historiadores e a gestão documental"; "A pesquisa feita por historiadores que trabalham em arquivos"; "Os historiadores e o atendimento aos usuários" - que refletiram sobre as atividades desenvolvidas em entidades que custodiam acervos arquivísticos (ASSOCIAÇÃO NACIONAL DE HISTÓRIA, 2012). Sobre estas atividades, foram consideradas as seguintes situações: "aquelas que devem contar com a presença de historiadores profissionais, aquelas nas quais a participação de historiadores é fortemente recomendável e aquelas cuja atuação destes profissionais agrega significativo valor" (ASSOCIAÇÃO NACIONAL DE HISTÓRIA, 2012). Nesta ocasião, conclui-se que:

[...] a presença de historiadores é imprescindível ao bom funcionamento dessas entidades custodiadoras, devendo esses profissionais atuarem nas diversas áreas e processos executados por essas instituições, compondo as equipes multidisciplinares responsáveis pelo seu funcionamento, em colaboração com profissionais de outras áreas, especialmente com os arquivistas. Também foi destacada a importância da inclusão de disciplinas e atividades voltadas ao tema nos currículos dos cursos de História a fim de que esses possam qualificar e aprofundar a formação de profissionais capazes de atuar em arquivos e entidades congêneres (ASSOCIAÇÃO NACIONAL DE HISTÓRIA, 2012).

Na história das profissões, as "fronteiras jurisdicionais das profissões estão sempre em disputa" (CRIVELLARI; CUNHA, 2009, p. 141). É a definição destes limites jurisdicionais entre as profissões que estabelece e controla a divisão do trabalho entre elas (CRIVELLARI; CUNHA, 2009). A Arquivologia é um campo interdisciplinar, no qual é importante que Arquivistas e Historiadores trabalhem em colaboração, uma vez que ambos são construtores de memória social.

De certa forma, os desafios contemporâneos impostos pela Arquivologia e pela História, assim como as questões relacionadas à memória, ao patrimônio documental e à pesquisa histórica, colocam em destaque a necessidade do resgate de uma parceria há muito perdida. Desde o final do século XIX, quando ambas as disciplinas passaram a trilhar caminhos separados $\mathrm{e}$ divergentes, o crescente desconhecimento entre a História e a Arquivologia trouxe grandes perdas a ambas. Não se trata de capacitar o profissional de História a exercer as funções de um arquivista, mas de salientar a importância de aprofundar a formação dos historiadores para capacitá-los a atuar como pesquisadores e como profissionais nas instituições de custódia documental ao lado dos arquivistas (MIRANDA, 2012, p. 909).

Posterior à regulamentação da profissão do Arquivista, a Lei no 7.287/84 regulamentou a profissão de Museólogo no Brasil. Esta Lei também autorizou a criação do Conselho Federal e dos Conselhos Regionais de Museologia, o que não ocorreu na lei que regulamentou a profissão de Arquivista. Bruno (1997) considera fundamental a revisão desta Lei, uma vez que "ela está totalmente distante do que a teoria museológica considera como básico, para o 
exercício profissional, como também não corresponde às necessidades da atual realidade brasileira" (BRUNO, 1997, p. 20-21).

O mercado de trabalho do Museólogo ultrapassa os espaços dos museus, mas nem sempre isto foi compreendido. Deste modo, "definia-se o campo de ação e mercado de trabalho do museólogo exclusivamente como o Museu; e, simultaneamente, o Museu não constituía o campo de trabalho exclusivo, ou mesmo preferencial (privilegiado) do museólogo" (GUARNIERI, 2010, p. 218). A falta de profissionais formados em Museologia e o caráter interdisciplinar da área resultaram em um pretexto para "alijar [o Museólogo] de seu campo de trabalho profissional, mesmo onde ele existia" (GUARNIERI, 2010, p. 218). Assim, embora a profissão de Museólogo seja regulamentada, a prática museal ainda não está reconhecida na sociedade, uma vez que o reconhecimento social não é automático:

Ocorreu o reconhecimento em plano legal pela aprovação das Leis que a regulamentam. Torna-se necessário, como em qualquer campo do conhecimento de formação recente, que se realize a consolidação das idéias do plano teórico e prático da Museologia para ser identificado o seu papel cultural e disseminá-lo junto a sociedade, a fim de que o Museólogo possa ser amplamente reconhecido pelo tecido social composto pelos profissionais dos demais campos do conhecimento e por outros grupos que usufruem dos seus serviços.

O contexto acadêmico e de investigação nas universidades e institutos de pesquisa, o ambiente das práticas em museus e seu efetivo alcance junto aos mais variados atores sociais, a ação das entidades de representação profissional (conselhos e associações) junto com normas e leis que regulamentam o exercício da profissão é o conjunto que favorece o reconhecimento social da ação profissional (COSTA; LIMA, 2013).

O mercado de trabalho do Museólogo foi alvo de reflexões de Guarniere (2010) e abaixo se apresenta apenas o primeiro tópico das conclusões:

1. Julgo que a regulamentação da profissão, embora condição necessária para a salvaguarda dos direitos do museólogo, não é suficiente para a plena conquista do mercado de trabalho.

1.1 Além de regulamentar a profissão é necessário lutar pela criação do lugar, do espaço profissional, através da criação de cargos e função, inclusive de chefia e direção.

1.2 Há que se cogitar da valorização do museólogo em termos de estabelecimento de salário compatível, sistemas de promoções etc.

1.3 Há que se cogitar de uma hierarquia de cargos e funções museológicas, contemplando não apenas as direções e chefias, mas lembrando a multiplicidade dos tempos sociológicos brasileiros e as profundas diferenças regionais, para que não se perca o patrimônio cultural e a herança do povo brasileiro onde apenas for possível o aproveitamento a curto e médio prazo de profissionais de nível médio e, mesmo, apenas pessoas treinadas ou que tenham recebido a "capacitação profissional" supletiva da formação adequada e ideal (GUARNIERE, 2010, p. 222-223).

A profissão é decorrência da influência mútua que ocorre no mercado de trabalho e "dos espaços que se disputam, se conquistam e se perdem. É na dimensão da história da profissão que podemos detectar como ela vem se desenvolvendo, para diagnosticar suas vitórias e suas derrotas" (BONELLI, 1993, p. 44). 


\section{As profissões na sociedade democrática e a organização profissional}

Rodrigues (2006) utiliza as ideias de Eliot Freidson para refletir como a instituição profissão articula-se em defesa dos regimes democráticos e do interesse público. Neste sentido, Rodrigues (2006) discorre sobre a forte desconfiança social em relação às profissões no Brasil e levanta a hipótese de que tal situação pode ser justificada pelo fato de que "o fenômeno das profissões regulamentadas esteve muito associado à construção dos regimes autoritários e corporativos, num passado ainda recente" (RODRIGUES, 2006, p. 270).

As regulamentações das profissões de Arquivista e Museólogo ocorreram durante o regime militar brasileiro, sendo a lei que regulamentou a primeira profissão publicada em 1978, no Governo do presidente Ernesto Geisel, e a segunda profissão em 1984, no Governo do presidente João Figueiredo. Ástrea de Moraes e Castro, que era Arquivista da Câmara dos Deputados, ressaltou sua participação no movimento associativo de Arquivistas, sua articulação junto ao diretor de ensino superior do Conselho Federal de Educação, Vicente Sobriño Porto, para a aprovação da graduação em Arquivologia e assegurou que "acionou as influências de Amália Lucy Geisel, filha do militar presidente da república Ernesto Geisel, para que a regulamentação da profissão acontecesse em 1978" (SILVA; ORRICO, 2012, p. 107).

Há um aumento dos grupos ocupacionais, dos membros dos grupos, das profissões regulamentadas e dos grupos ocupacionais que desejam o estatuto de profissão, segundo Rodrigues (2006). A autora destaca que o crescimento das profissões está associado ao crescimento do ensino Superior, ocorrido a partir dos anos 70 (RODRIGUES, 2006). Desde o surgimento das primeiras profissões de nível Superior no país, observa-se a regulamentação das profissões que estão na área ou na fronteira do novo curso criado (BONELLI, 1993). Segundo Oliveira e Crivellari (2013), "a regulamentação profissional favorece o reconhecimento e a estabilidade do grupo social".

O aumento de profissionais no interior de cada grupo ocupacional implica consequências sobre a composição interna dos grupos (o recrutamento dos profissionais passa a abarcar, por exemplo, mulheres, indivíduos de diversas origens étnicas e sociais), proporcionando novas segmentações internas, e sobre as condições de exercício profissional (natureza dos trabalhos executados, condições de remuneração, inserção e percurso profissional e das carreiras, por exemplo), o modo como as profissões se relacionam e se integram no mercado de trabalho (RODRIGUES, 2006). Essas duas alterações nas profissões e no mercado de trabalho suscitaram algumas teses que indicam para a degradação do fenômeno das profissões e do estatuto profissional e para a tendência à desprofissionalização. Frente a estas teses, Rodrigues (2006) faz duas ressalvas:

Primeira nota: as análises sobre as condições de exercício, de remuneração e de acesso às profissões ganharão se forem articuladas com a análise dos 
efeitos de dimensão, de crescimento e de heterogeneidade interna nas situações dos profissionais no mercado de trabalho. Em todos os grupos profissionais coexistem profissionais muito bem remunerados e com posições de poder e prestígio, com profissionais com baixas remunerações e ocupados em funções menos prestigiadas. Por outro lado, a relação entre o estatuto profissional e a situação de exercício profissional, em particular com a integração em organizações públicas ou privadas, requer uma atenção sistemática. Sendo os grupos profissionais internamente segmentados e hierarquizados, não podemos, nunca, tomar a parte pelo todo, sob risco de cairmos em generalizações abusivas.

Segunda nota: só a análise diacrónica ou temporal permite avaliar em que medida os mecanismos ditos de desprofissionalização funcionam, para o conjunto da profissão, como mecanismos de reforço do poder profissional, de alargamento da base de recrutamento e do campo de acção dos profissionais. Revela-se, assim, essencial, no estudo das profissões, a comparação no tempo ou no espaço dos fenómenos que se pretendem analisar (RODRIGUES, 2006, p. 273).

Feitas estas ressalvas, Rodrigues (2006) conclui que as alterações dentro de uma profissão, reforçadas por mudanças tecnológicas, mercadológicas e por mudanças realizadas pelo Estado, tais como as políticas públicas, desdobram-se em consequências geográficas e setoriais diversas. Há casos em que ocorre a criação de espaços de afirmação do profissionalismo, com a criação de postos ou funções que aumentam a autonomia e a responsabilização dos agentes. E, por outro lado, há também casos de criação de espaços de desprofissionalização, com a criação de postos de trabalho que dispersam e desvalorizam as capacidades e competências do trabalhador.

Os críticos contrários às profissões e aos profissionalismos baseiam-se em estudos que apontam uma função social negativa como característica das profissões, uma vez que "por detrás da ideologia do profissionalismo, desenvolver-se-iam mecanismos de fechamento social e de exclusão, originando e reproduzindo situações de dominação de privilégio e de desigualdade social e económica" (RODRIGUES, 2006, p. 274). Em perspectiva oposta, os defensores da função social positiva das profissões, a favor das profissões e dos profissionalismos, utilizam os seguintes argumentos:

Em primeiro lugar, destaca-se que as profissões assentam num sistema de regras e de valores modernos, como os da racionalidade e do conhecimento, da meritocracia, da igualdade de oportunidades, do bem-estar social e da justiça, os quais se articulam de forma coerente com os sistemas de regras dominantes nas sociedades modernas e democráticas. Em segundo lugar, que no sistema de regras e de valores em que as profissões assentam estão inscritos [sic] a motivação altruística e a orientação da acção pelo desenvolvimento do conhecimento, da realização competente, da melhoria da qualidade dos serviços prestados e pela defesa do interesse público, e que estas motivações não são sempre, nem forçosamente, incompatíveis com o auto-interesse do profissional. Em terceiro lugar, considera-se que as profissões constituem uma forma alternativa de organização do trabalho e de autoridade baseada no conhecimento, e não em características individuais (como a raça, o sexo ou a idade), ou em recursos herdados (como a propriedade de capital ou a origem social). Finalmente, em quarto lugar, defende-se que o monopólio e o credencialismo, são elementos-chave dos privilégios económicos dos profissionais, mas são também elementos-chave 
na realização de trabalho competente, no desenvolvimento do conhecimento e dos saberes profissionais. O controlo da formação, da certificação e da prática profissional está na base também dos elevados padrões de qualidade alcançados em muitas áreas de conhecimento (RODRIGUES, 2006, p. 274275).

Rodrigues (2006) aponta que o debate em torno dessas duas perspectivas sobre a função social das profissões tem sido utilizado na análise de privatizações de sistemas públicos e na avaliação de seus resultados. Grandes grupos profissionais com interesses nas ondas de privatizações advogam que a ineficiência e a improdutividade devem-se à defesa dos interesses próprios do corporativismo profissional e que tal situação seria revertida se submetida à lógica do mercado e da economia privada e que se for necessário adotar o modelo burocrático administrativo, este deve ser chefiado por gestores, e não por profissionais.

Os resultados das ondas de privatizações foram submetidos à avaliação e, de modo geral, conclui-se que as privatizações desorganizaram o serviço público e diminuíram a sua qualidade (RODRIGUES, 2006). O estudo desta avaliação revelou que os grupos profissionais podem ser vistos como defensores do interesse público, uma vez que valorizam e prezam: pela qualidade e universalidade dos serviços profissionais; pelos critérios de competência para o desenvolvimento dos conhecimentos, da independência de julgamento e da ação na prestação dos serviços profissionais (RODRIGUES, 2006). Assim, marca-se a oposição e resistência dos grupos profissionais às "lógicas de mercado, aos argumentos da eficiência e da redução dos custos quando estes se revelaram incompatíveis com a qualidade e a realização competente, com a autonomia e, portanto, com o interesse público" (RODRIGUES, 2006, p. 276).

Contudo, a autora afirma que essa conclusão não tem sido suficiente para reestabelecer a confiança, uma vez que há várias ambivalências, tensões no universo das profissões, dentre elas a autora cita as seguintes:

- a tensão entre abertura e fechamento social, ou seja, a tensão resultante da aplicação de normas que visam garantir o princípio democrático da igualdade de oportunidades especificada, por exemplo, no acesso ao ensino e às profissões, em conflito com os movimentos de protecção de interesses, de fechamento dos mercados de serviços profissionais, minimizando os processos de perda de privilégios e a degradação das condições de trabalho; - a tensão entre massificação e especificação meritocrática, ou seja, a tensão entre os processos de massificação que resultam da extensão de direitos e garantias individuais básicos e a diferenciação resultante do mérito e/ou da desigual distribuição de outros recursos;

- a tensão entre autonomia e controlo, ou seja, a tensão entre o poder de decisão dos profissionais na resolução de problemas (poder assente na autoridade dos saberes e competências técnicos) e a necessidade de institucionalização de mecanismos de responsabilização individual e de controlo social dos processos e dos resultados;

- a tensão entre interesse público e interesse privado, ou seja, a tensão resultante da sobreposição (ou da ausência de clarificação) dos interesses, muitas vezes antagónicos, do bem público, do Estado, dos cidadãos, de grupos económicos organizados, de membros do grupo profissional, da 
associação que os representa ou do seu líder (RODRIGUES, 2006, p. 276277).

A autora ressalta que se deve almejar não simplesmente as superações das tensões apontadas acima. O que se deve buscar é "a construção de equilíbrios que sejam compatíveis com o funcionamento das sociedades democráticas" (RODRIGUES, 2006, p. 277). A extensão do credencialismo e das situações de monopólio indicam tendências para "generalizar não apenas a exigência de diplomas e de formação formal como condição de acesso a determinadas áreas de actividade, mas também a aspiração à criação de situações de monopólio ou de protecção de mercado" (RODRIGUES, 2006, p. 277). Os excessos das tendências do credencialismo podem resultar na rejeição do reconhecimento da experiência, como meio de adquirir competências, produzindo uma uniformização social, que sujeita a formação (nas instituições de ensino) apenas ao mercado profissional. Já os excessos cometidos na proteção de mercados (monopólios) colocam em risco a participação ampla da sociedade no mercado de trabalho. Para garantir a democracia, destaca-se a importância do equilíbrio no que concerne tanto ao credencialismo quanto ao monopólio (RODRIGUES, 2006).

A busca por estes equilíbrios e pela confiança pública nas profissões pode ser conduzida pelas instituições de representação profissional (conselhos, sindicatos, ordens, etc). Estas instituições devem elaborar instrumentos que garantam a defesa do interesse público e a confiança nelas mesmas, tais como código de ética profissional e mecanismos de controle profissional. A organização dos profissionais em grupos, como, associações, sindicatos e conselhos, reflete em envolvimento comunitário e em laços de reciprocidade e confiança. As práticas colaborativas e a participação de indivíduos que acreditam no trabalho coletivo e no civismo resultante desta ação são o reflexo da organização profissional. As ações colaborativas desenvolvidas pelos grupos profissionais organizados são fundamentais para a afirmação da identidade profissional.

"As associações, de caráter civil, são independentes do Estado, enquanto os sindicatos e os conselhos regionais e federal estão vinculados ao Ministério do Trabalho, constituindo-se em veículo de controle estatal" (OLIVEIRA, 2012, p. 26). Os Conselhos profissionais são criados para fiscalizar o exercício profissional para garantir o interesse da sociedade. Assim, "se o Estado entende que uma atividade profissional deva ser regulamentada, urge, mesmo que num posterior momento, a necessidade da criação de Conselhos Federal e Regionais para fiscalizar esse exercício profissional" (COSTA; VALENTE, 2008, p. 5). Deste modo, a ação dos conselhos deve ser guiada pela proteção da coletividade e não pelos interesses da categoria profissional organizada. Criados por lei, os conselhos profissionais são caracterizados juridicamente como autarquias, da administração pública indireta, dotadas de personalidade de direito público, que exercem poder de polícia 
sobre as respectivas profissões regulamentadas. "Com efeito, as entidades de fiscalização profissional, no exercício do poder de polícia, devem zelar pela preservação de dois aspectos essenciais, que são a ética e a habilitação técnica adequada para o exercício profissional" (COSTA; VALENTE, 2008, p. 8).

Os Museólogos dispõem do Conselho Federal de Museologia, e vinculam-se a este, seis Conselhos Regionais de Museologia, sendo a representação através do conselho a forma mais significativa para os Museólogos. Os Arquivistas, entretanto, não possuem esta entidade e o exercício da profissão depende de registro na Delegacia Regional do Trabalho (BRASIL, 1978). É importante esclarecer que o Conselho Nacional de Arquivos é um órgão vinculado ao Arquivo Nacional, o qual define a política nacional de arquivos; não correspondendo, portanto, a uma instituição de representação profissional.

O sindicato, no Brasil, é regulado pelo Decreto-Lei no 1.402/1939, sendo uma forma de associação profissional para representar o empregado. Não há um sindicato para os Museólogos, no entanto, em São Paulo, existe o Sindicato dos Bibliotecários, Cientistas da Informação, Historiadores, Museólogos, Documentalistas, Arquivistas, Auxiliares de Biblioteca e de Centros de Documentação do Estado de São Paulo (SINBIESP).

A Associação Brasileira de Museologistas - depois o nome foi modificado para Associação Brasileira de Museologia (COSTA; LIMA, 2013) - foi criada em 1963, com o intuito de "dignificar e proteger os profissionais de museus no país" (MORAES; SOUZA, 2013, p. 16), que enfrentavam carência de ações governamentais para a área cultural. A classe arquivística brasileira certamente é mais bem representada pelas associações estaduais de Arquivistas, que lutam pelos interesses corporativistas de seus associados. De acordo com o Código Civil brasileiro, as associações são pessoas jurídicas de direito privado, sem fins econômicos. Todas as associações estaduais arquivísticas estão congregadas, desde 2014, no Fórum Nacional das Associações de Arquivistas do Brasil (FNArq), que é um colegiado que reúne, coordena e representa os interesses das associações.

\section{Considerações finais}

Neste artigo, destacou-se que o diploma de nível superior é um critério determinante, para várias correntes sociológicas, para distinguir os conceitos de profissão e ocupação. As jurisdições no âmbito profissional foi outro conceito desenvolvido nesta reflexão teórica.

O Estado exerce um papel relevante nas determinações profissionais, por meio, por exemplo, dos mecanismos legais de regulamentação profissional, da delegação de autoridade aos conselhos de classe e da criação de cursos universitários. No Brasil, as profissões de Arquivista e Museólogo são regulamentadas e a oferta de cursos universitários que formam estes profissionais foi expandida pelo Estado, através do Programa de Apoio a Planos de Reestruturação e Expansão das Universidades Federais. 
Este trabalho demonstrou que cada grupo profissional possui um campo de atividade exclusivo (heartland) e possui também uma área suplementar de atividade (hinterland e horizon), sendo este um campo residual de atuação profissional, na qual as profissões concorrem pelo mercado de trabalho (GUARNIERI, 2010). O controle legal sobre as profissões de Arquivistas e Museólogos, por meio da formação universitária e da regulamentação profissional, garante-lhes o exercício jurisdicional sobre certas atividades exclusivas, mantendo esses grupos profissionais protegidos da incursão de outros grupos ao seu campo de atividades. O que, no entanto, não os exime da investida de alguns grupos, como, por exemplo, dos Historiadores na luta pela regulamentação profissional, pois a disputa é uma característica estrutural da configuração do campo das profissões.

Na reflexão teórica aqui apresentada, ficou evidente que as organizações profissionais exercem um importante papel na coletividade - considerando tanto os profissionais, quanto os usuários - e na definição da identidade profissional. O campo museológico está melhor representado pelo Conselho Federal de Museologia e pelos Conselhos Regionais de Museologia. Ao passo que as associações estaduais é o tipo de organização profissional que se sobressai no campo arquivístico. Este trabalho também indicou que as profissões estão relacionadas à defesa dos regimes democráticos e do interesse público e que as organizações profissionais são as responsáveis pela definição de laços de confiança púbica nas profissões e entre os profissionais.

\section{REFERÊNCIAS}

ABBOTT, A. The System of Profession: An Essay on the Division of Expert Labor. Chicago: University of Chicago Press, 1988.

ALVES, T. S. A Família ocupacional "Arquivistas e Museólogos": posicionamento na Classificação Brasileira de Ocupações e perfil de emprego. Belo Horizonte, 2016. $197 f$. Dissertação (Mestrado em Ciência da Informação) - Escola de Ciência da Informação, Universidade Federal de Minas Gerais, 2016.

ASSOCIAÇÃO NACIONAL DE HISTÓRIA. O perfil profissional dos Historiadores atuantes em arquivos. São Paulo: ANPUH, 2012. Não paginado.

BARBOSA, M. L. O. A sociologia das profissões: em torno da legitimidade de um objeto. BIB, Rio de Janeiro, n. 36, p. 3-30, 2 sem., 1993.

BONELLI, M. G. As ciências sociais no sistema profissional brasileiro. BIB, Rio de Janeiro, n. 36, p. 31-61, 2 sem., 1993.

BRASIL. Lei no 6.546 , de 4 de julho de 1978. Dispõe sobre a regulamentação das profissões de Arquivista e de Técnico de Arquivo, e dá outras providências. Diário Oficial da União, Brasília, 5 jul. 1978. 
Projeto de Lei no 4.699, de 09 de novembro de 2012. Regulamenta a profissão de historiador e dá outras providências. Brasília: Senado Federal, 2012. Disponível em: $<$ http://www.camara.gov.br/proposicoesWeb/prop mostrarintegra;jsessionid=2FB9F5BFC32 808E3F51E4773CDED59CE.proposicoesWeb1 ?codteor $=1038347$ \&filename $=P L+4699 / 2012$ >. Acesso em: 12 maio. 2019.

BRUNO, M. C. O. Teoria Museológica: a problematização de algumas questões relevantes à formação profissional. Cadernos de Sociomuseologia, n. 10, p.13-21, 1997.

COSTA, B. R. M.; VALENTE, M. A. L. Responsabilidade social dos Conselhos Profissionais. Brasília: Câmara dos Deputados; Consultoria Legislativa, 2008.

COSTA, L. L. M.; LIMA, D. F. C. O termo museólogo e seu conceito: análise da atividade profissional em coleções de artistas plásticos contemporâneos. In: ENCONTRO NACIONAL DE PESQUISA EM CIÊNCIA DA INFORMAÇÃO, 14, 2013, Florianópolis. Anais... Florianópolis: UFSC, 2013. Não paginado.

CRIVELLARI, H. M. T.; CUNHA, M. V. da. Os bibliotecários como profissionais da informação: estratégias e paradoxos de um grupo profissional. In: ENCONTRO ANUAL DA ASSOCIAÇÃO NACIONAL DE PÓS-GRADUAÇÃO E PESQUISA EM CIÊNCIAS SOCIAIS, 28, 2004, Caxambu. Anais... Caxambu: ANPOCS, 2004. 1 CD-ROM.

Reflexões sobre o grupo de trabalho (GT-6) do Encontro Nacional de Pesquisa em Ciência da Informação (ENANCIB) - Informação, educação e trabalho: um olhar a partir da sociologia das profissões e da sociologia do trabalho. Tendências da Pesquisa Brasileira em Ciência da Informação, Brasília, v. 2, n. 1, p. 135-154, jan./dez. 2009.

CUNHA, M.V.; CRIVELLARI, H. M. T. O mundo do trabalho na sociedade do conhecimento e os paradoxos das profissões da informação. In: VALENTIM, M. L. (Org.). Atuação profissional na área de informação. São Paulo: Polis, 2004. p. 39-54.

DUARTE, Z. Arquivo e arquivista: conceituação e perfil profissional. Revista da Faculdade de Letras Ciências e Técnicas do Patrimônio, Porto, v. V-VI, série I, p.141-151, 2006-2007. FONSECA, M. O. Arquivologia e ciência da informação. Rio de Janeiro: FGV, 2005.

GUARNIERI, W. R. C. O mercado de trabalho do museólogo na área da Museologia. In: BRUNO, M. C. O. (Coord.); ARAÚJO, M. M. (Col.); COUTINHO, M. I. L. (Col.). Waldisa Rússio Camargo Guarnieri: textos e contextos de uma trajetória profissional. São Paulo: Pinacoteca do Estado, Secretaria de Estado da Cultura; Comitê Brasileiro do Conselho Internacional de Museus, 2010, v. 1. p. 215-223.

MARQUES, A. A. da C. Interlocuções entre a Arquivologia nacional e a internacional no delineamento da disciplina no Brasil. 2011.339 f. Tese (Doutorado) - Programa de PósGraduação em Ciência da Informação - Universidade de Brasília, Brasília, 2011.

MIRANDA, M. E. Historiadores Arquivistas e Arquivos. In: Simpósio Nacional da ANPUH Associação Nacional de História, 26, 2011, São Paulo. Anais eletrônicos... São Paulo: ANPUH-SP, 2011. 
Os Arquivos e o ofício do Historiador In: ENCONTRO ESTADUAL DE HISTÓRIA, 11, 2012, São Paulo. Anais eletrônicos... São Paulo: FURG, 2012.

MORAES, N. A.; SOUZA, L. C. C. Museu e patrimônio: políticas e conhecimento. Museologia e Patrimônio, [Rio de Janeiro], v.6, n.2, 2013.

MUELLER, S. P. M. Uma profissão em evolução: profissionais da informação sob a ótica de Abbott - proposta de estudo. In: BAPTISTA, S. G.; MUELLER, S. P. M. (Org.). Profissional da informação: espaço de trabalho. Brasília: Thesaurus, 2004, p. 23-54.

OLIVEIRA, J. L. R. Estudo comparado entre bibliotecários, contadores e analistas de tecnologia da informação: processo de profissionalização e seus efeitos na formação, atuação e reconhecimento profissional. 2012. Tese (Doutorado em Ciência da Informação) Escola de Ciência da Informação, Universidade Federal de Minas Gerais, Belo Horizonte, 2012.

OLIVEIRA, J. L. R.; CRIVELLARI, H. M. T. Reconhecimento e estabilidade profissional: estudo comparado entre bibliotecários, contadores e analistas de Tecnologia da Informação. In: ENCONTRO NACIONAL DE PESQUISA EM CIÊNCIA DA INFORMAÇÃO, 14, 2013, Florianópolis. Anais... Florianópolis, 2013.

RODRIGUES, M. L. As profissões e a democracia. Pro-posições, Campinas, v. 17, n. 1, jan./abr. 2006.

Sociologia das profissões. Oeiras (Portugal): Celta, 2002.

SANTOS, P. R. E. A arquivística no laboratório: história, teoria e métodos de uma disciplina. Tese (Doutorado) - Programa de Pós-Graduação em História Social, Universidade de São Paulo, São Paulo. 2008.

SILVA, A. B. M. Arquivística, biblioteconomia e museologia: do empirismo patrimonialista ao paradigma emergente da Ciência da Informação. In: INTEGRAR - Congresso Internacional de Arquivos, Bibliotecas, Centros de Documentação e Museus, 1., 2002, São Paulo. Anais... São Paulo: Imprensa Oficial do Estado, 2002, p. 573-607.

SILVA, E. P.; ORRICO, E. G. Estado da arte na institucionalização do campo arquivístico no Brasil. In: MARIZ, A. C. A.; JARDIM, J. M.; SILVA, S. C. de A. (Org.). Novas dimensões da pesquisa e do ensino da arquivologia no Brasil. Rio de Janeiro: Móbile; Associação dos Arquivistas do Estado do Rio de Janeiro, 2012. p. 99-113.

SOUZA, K. I. M. Arquivista, visibilidade profissional: formação, associativismo e mercado de trabalho. Brasília: Starprint, 2011.

TANUS, G. F. S. C. Cenário acadêmico institucional dos cursos de arquivologia, biblioteconomia e museologia do Brasil. 2013. 242 f. Dissertação (Mestrado em Ciência da Informação) - Escola de Ciência da Informação, Universidade Federal de Minas Gerais, 2013. 